\title{
A Time-Saving Technique for Specimen Extraction in Sleeve Gastrectomy: Reply
}

\author{
Giovanni Casella $\cdot$ Emanuele Soricelli • \\ Aldo Fantini • Nicola Basso
}

Published online: 21 October 2010

(C) Société Internationale de Chirurgie 2010

We appreciate the interest of Attila Csendes in our article, which describes in detail a simple and standardized technique for the extraction of the specimen after laparoscopic sleeve gastrectomy (LSG) [1]. The aim of our study was not only to give a broader description of the technical aspects of the procedure but also to analyze the advantages of this technique in terms of cost, incidence of wound infection, and operative time. In contrast, in the article by Braghetto et al. [2] the authors make only short mention of the technique adopted for the extraction of the specimen: "The resected specimen is removed easily through the 15-mm port of the right upper abdominal quadrant." Furthermore their technique seems to be quite different from ours, as in our experience the specimen is removed through the "trocar site" and not "through the trocar."

In the literature many different, more expensive and more time-consuming procedures, such as the use of an Endobag or morcellation of the resected stomach, have been described by several authors [3-9]. In particular, Alley et al. in a recent paper [10] reported a new technique for extracting the gastrectomy specimen after LSG. They described "a low-technology technique for orienting the gastric specimen for easy extraction without port site enlargement: place a long 2-0 silk suture to the caudal tip of the specimen before placing it in a retrieval bag, inserted through the 15-mm trocar."

Therefore, although we take note of the opinion expressed by Csendes, we believe the maneuvres described in our article, even if very simple, represent an easily

G. Casella · E. Soricelli · A. Fantini · N. Basso $(\square)$ Surgical-Medical Department for Digestive Diseases, Policlinico "Umberto I", University of Rome "La Sapienza", Viale de Policlinico, 00161 Rome, Italy

e-mail: nicola.basso@uniroma1.it reproducible, time-saving, and cost-effective solution to the problem of specimen removal, especially because there is still a lack of consensus about the best approach, as reported in the literature. Apparently the Editorial Board of the World Journal of Surgery was of the same opinion.

\section{References}

1. Casella G, Soricelli E, Fantini A et al (2010) A time-saving technique for specimen extraction in sleeve gastrectomy. World $\mathrm{J}$ Surg 34:765-767

2. Braghetto I, Korn O, Vallardes H et al (2007) Laparoscopic sleeve gastrectomy: surgical technique, indication and clinical results. Obes Surg 17:1442-1450

3. Roa PE, Kaidar-Person O, Pinto D et al (2006) Laparoscopic sleeve gastrectomy as treatment for morbid obesity: technique and short-term outcome. Obes Surg 16:1323-1326

4. Jason Moy J, Pomp A, Dakin G et al (2008) Laparoscopic sleeve gastrectomy for morbid obesity. Am J Surg 196:56-59

5. Gagner M, Gumbs AA, Milone L et al (2008) Laparoscopic sleeve gastrectomy for the super-super-obese (body mass index $>60 \mathrm{~kg} / \mathrm{m}^{2}$ ). Surg Today 38:399-403

6. Baltasar A, Serra C, Pérez N et al (2005) Laparoscopic sleeve gastrectomy: a multi-purpose bariatric operation. Obes Surg 15: $1124-1128$

7. Cottam D, Qureshi FG, Mattar SG et al (2006) Laparoscopic sleeve gastrectomy as an initial weight-loss procedure for high risk patients with morbid obesity. Surg Endosc 20:859-863

8. Deitel M, Crosby RD, Gagner M (2008) The First International Consensus Summit for Sleeve Gastrectomy (SG), New York City, October 25-27, 2007. Obes Surg 18:487-496

9. Mahmood A, Silbergleit A (2006) The utilization of a morcellator during laparoscopic sleeve gastrectomy. Technol Health Care 14:537-539

10. Alley JB, Fenton SJ, Peterson RM (2009) The “tip-stitch": a time-saving technique for specimen extraction in sleeve gastrectomy. Obes Surg 19:926-927 